\title{
Transparency in medicines regulatory affairs - reclaiming missed opportunities
}

\author{
Y A Vawda, ${ }^{1}$ BA, BProc, LLM, LLD; A Gray, ${ }^{2}$ BPharm, MSc (Pharm), FPS, FFIP \\ 'School of Law, College of Law and Management Studies, University of KwaZulu-Natal, Durban, South Africa \\ ${ }^{2}$ Division of Pharmacology, Discipline of Pharmaceutical Sciences, University of KwaZulu-Natal, Durban, South Africa
}

Corresponding author: Y A Vawda (VAWDAY@ukzn.ac.za)

\begin{abstract}
Transparency is a salutary value in South Africa (SA)'s constitutional architecture. It has also been described as a necessary element in promoting accountability in the regulatory aspects of essential medicines. Nevertheless, despite its several incarnations since its promulgation, the Medicines and Related Substances Act No. 101 of 1965 retains a 'preservation of secrecy' provision (section 34). This contribution seeks to evaluate section 34 in the context of transparency; to ascertain whether it is in conflict with other legislation pertaining to the promotion of access to information; and, in particular, to establish whether it is consistent with the Constitution of the Republic of SA.
\end{abstract}

S Afr J Bioethics Law 2017;10(2):70-74. DOI:10.7196/SAJBL.2017.v10i2.607

Transparency is a salutary value in South Africa (SA)'s constitutional architecture. ${ }^{[1]}$ It has also been described as a necessary element in promoting accountability in essential medicines selection, quality assurance, improvement of use, and priority setting for research and development. ${ }^{[2]}$ One of the institutions providing an important public function in every country is the national medicines regulatory authority (NMRA). In SA, this function is in the process of being transferred from the Medicines Control Council (MCC) to the SA Health Products Regulatory Authority (SAHPRA). However, despite amendments in 1997, $,^{[3]} 2002,{ }^{[4]} 2008,{ }^{[5]}$ and 2015, ${ }^{[6]}$ the Medicines and Related Substances Act No. 101 of $1965^{[7]}$ (Medicines Act) retains a provision headed 'Preservation of secrecy' (section 34). This brief review seeks to evaluate section 34 of the Medicines Act in the context of transparency, and to ascertain whether it is in conflict with other legislation pertaining to the promotion of access to information and, in particular, whether it is consistent with the Constitution of the Republic of SA (the Constitution). ${ }^{[1]}$ In order to establish the constitutionality of this provision, it is necessary to explore the following series of linked questions:

(i) What is the extent of the limitations on transparency in section 34 of the Medicines Act?

(ii) Is section 34 so excessively broad as to infringe on the constitutional right to access to information?

(iii) If so, can such an infringement be justified?

(iv) Does section 34 amount to an undue prohibition of access to information that is in the public interest, as envisioned in the Promotion of Access to Information Act No. 2 of 2000 (PAIA)? ${ }^{[8]}$

\section{The Constitution}

Any informed view of the statutory provision under scrutiny must consider the constitutional perspective. With regard to access to information, the relevant provision is section 32 of the Constitution, ${ }^{[1]}$ which states:
'(1) Everyone has the right of access to -

(a) any information held by the state; and

(b) any information that is held by another person and that is required for the exercise or protection of any rights.'

Given the supremacy of the Constitution, a provision in any law that is in conflict with it is unconstitutional, and therefore unlawful. The primacy of constitutional rights has been established in several court decisions. In S v Zuma, ${ }^{[9]}$ these rights were given the most generous possible interpretation. The court made particular reference to the Canadian case of Regina v Big M Drug Mart Ltd.. ${ }^{[10]}$ in which it was stated: 'The meaning of a right or freedom guaranteed by the Charter was to be ascertained by an analysis of the purpose of such a guarantee; it was to be understood, in other words, in the light of the interests it was meant to protect.' The constitutional perspective was further articulated in S v Makwanyane, ${ }^{[1]]}$ where the Constitutional Court emphasised a contextual approach to interpretation, which included reviewing the history and background of the Constitution, other provisions within it and the values it represents.

However, constitutional rights are not absolute, and in limited circumstances can be infringed upon, without invalidating the offending provision. This principle is specifically provided for in section 36 (the limitation of rights clause ${ }^{[1]}$ which states:

'(1) The rights in the Bill of Rights may be limited only in terms of law of general application to the extent that the limitation is reasonable and justifiable in an open and democratic society based on human dignity, equality and freedom, taking into account all relevant factors, including:

(a) the nature of the right;

(b) the importance of the purpose of the limitation;

(c) the nature and extent of the limitation;

(d) the relation between the limitation and its purpose; and

(e) less restrictive means to achieve the purpose.' 
In view of the significance of rights and the protections they afford, if any provision appears to infringe upon a right it is prima facie unconstitutional, and therefore the duty rests on the infringing party to demonstrate that it has satisfied the test elaborated in section 36 , as stated in $S$ v Makwanyane..$^{[1]]}$ In making the determination of whether an infringement is justified, the Canadian court in $R \mathrm{v}$ Chaulk ${ }^{[12]}$ set out the reasonable limit test following the case of $R v$ Oakes, ${ }^{[13]}$ which held that the objective of the infringement must be of sufficient importance, the means being used must be rationally connected to the objective, it should impair rights as minimally as possible and the effects of the limitation should be proportional to the objective. While South African constitutional jurisprudence shares many features with its Canadian counterpart, such as a twostage limitations analysis, it has not adopted the reasonable limit test, opting instead for a multifactor balancing approach. This confers a wide discretion on the courts, enabling them to sometimes adopt a test for rationality (deciding whether the limitation is reasonable) and, at other times, a test for reasonableness (considering rationality and proportionality). ${ }^{[14]}$

Section 32 makes specific reference to information held by the state. In deciding whether the MCC or SAHPRA is an 'organ of state', recourse must be had to section $239^{[1]}$ of the Constitution, which reads:

'Organ of state' means (a) any department of state or administration in the national, provincial or local sphere of government; or (b) any other functionary or institution:

(i) exercising a power or performing a function in terms of the Constitution or a provincial constitution; or

(ii) exercising a public power or performing a public function in terms of any legislation, but does not include a court or a judicial officer.'

As institutions performing a public function in terms of legislation, namely the Medicines Act, both qualify as organs of state, and consequently are subject to the obligations placed on them by the Constitution and other legislation. In addition, SAHPRA has been designated as a schedule $3 \mathrm{~A}$ national public entity in terms of the Public Finance Management Act No. 1 of 1999. ${ }^{[15]}$

\section{The Promotion of Access to Information Act}

Section 32 is a key provision in the Constitution, as it has been held that access to information is crucial to the right of freedom of expression, and that the public must have access to information held by the state. ${ }^{[14]}$ The right to access to information in section 32 of the Constitution is given effect to in section 9 of $\mathrm{PAIA}_{1}^{\left[{ }^{[8]}\right.}$ which deals with the objects of the Act:

'(a) to give effect to the constitutional right of access to

(i) any information held by the state; and

(ii) any information that is held by another person and that is required for the exercise or protection of any rights'.

PAIA is premised on the notion that access to information is essential to a liberal constitutional democracy, because transparency of state entities and public bodies promotes accountability and deters corruption and the abuse of power. For this reason, it endeavours to provide for access to any information held by the state, as opposed to access to information held by private bodies, which is limited to instances for the exercise and protection of any rights. This is reinforced by the strong and definitive wording of section 11 of PAIA, ${ }^{[8]}$ dealing with public bodies, which provides that:

'(1) a requester must be given access to a record of a public body if:

(a) that requester complies with all the procedural requirements in

this Act relating to a request for access to that record; and

(b) access to that record is not refused in terms of any ground for refusal contemplated in Chapter 4 of this Part.' (emphasis added).

In certain instances, there is a justifiable interest in protecting information held by public bodies from being disclosed. Such instances are dealt with in Chapter 4 of Part 2 of PAIA, pertaining to the grounds of refusal of access to records, which prescribes the grounds both upon which an information officer of a public body must refuse, as well as instances where he may refuse, a request to access a record. Therefore, section 43 provides for the mandatory protection of the research information of a third party, and may require the protection of such information relating to a public body. These protections must, however, be weighed against section $46,{ }^{[8]}$ which deals with mandatory disclosure in the public interest, and which states:

'Despite any other provision of this Chapter, the information officer of a public body must grant a request for access to a record of the body contemplated in [various sections listed] if -

(a) the disclosure of the record would reveal evidence of -

(i) a substantial contravention of, or failure to comply with, the law; or

(ii) an imminent and serious public safety or environmental risk; and

(b) the public interest in the disclosure of the record clearly outweighs the harm contemplated in the provision in question.'

An NMRA is required, for instance, by Article 39 of the World Trade Organization's agreement on Trade-Related Aspects of Intellectual Property Rights to protect undisclosed trial data against 'unfair commercial use,' 'except where necessary to protect the public.! ${ }^{[16]}$ The decision in SA Airlink v Mpumalanga Tourism and Parks Agency ${ }^{[17]}$ illustrates the manner in which the courts have dealt with competing interests when considering the issue of access to information. The court held that, where a state body seeks to refuse access to information to the public, the burden rests on the person refusing access to establish that the refusal is justified under PAIA. ${ }^{[17]}$ The court also considered refusal to grant access to information where doing so would be likely to cause harm to the commercial and financial interests of a third party. On this issue, the court held that in order for such a refusal to be justified the harm must not only be possible, but probable. In other words, it is not sufficient for a body to refuse to disclose information because there is some chance of harm to a third party, no matter how remote, as this would constitute an arbitrary infringement of a fundamental right. In order for state bodies to refuse to disclose information on the basis of a possible harm or setback to a third party, the duty is on the person refusing to show why this harm is serious and likely to materialise. The court also held that the mere existence of a confidentiality clause in an agreement 'cannot shield the agreement from disclosure. ${ }^{[17]}$ Furthermore, refusals cannot be justified by the mere fact that the requests made were too broad, as was held in the case of Biowatch Trust v Registrar Genetic 
Resources and Others. ${ }^{[18]}$ If the state body in question is of the opinion that a request is not sufficiently specific, it is under an obligation to assist the person who made the request in identifying the document or documents sought. It cannot simply dismiss requests and so deny a right to access to information on the grounds of ambiguity of the request, and there is a positive onus upon the state body to make a bona fide effort to clarify the information the requester is seeking, failing which the refusal will be unjustified. In this case, the court expressed a similar sentiment to that in the SA Airlink case regarding refusals. It stated that although confidentiality of information and potential violation of third parties' rights are legitimate concerns, they cannot serve as grounds to bar access to all requested information. ${ }^{[18]}$

\section{Section 34 of the Medicines Act}

Section 34 of the Medicines Act ${ }^{[7]}$ provides that:

'No person shall, except for the purpose of the exercise of his powers or the performance of his functions under this Act, or for the purpose of legal proceedings under this Act, or when required to do so by any competent court or under any law, or with the written authority of the Director-General, disclose to any other person any information acquired by him in the exercise of his powers or the performance of his functions under this Act and relating to the business or affairs of any person, or use such information for self-gain or for the benefit of his employer.'

The wording in this section is peremptory, particularly the use of the word 'shall', and does not permit any disclosure of information except when specifically authorised by the Act. The purpose of this provision appears to be to prevent persons who work for and perform some function within the MCC (and now SAHPRA) from disclosing to unauthorised persons the information they gather in the course of their work, and from using such information for their own gain or profit. This, in itself, is perfectly rational, considering the sensitive nature of some of the information such persons might have access to, and for the risk of serious prejudice that such disclosure could cause to the persons and bodies to which the information pertains. The major concern for any NMRA is to protect information that is considered 'commercial in confidence', and therefore not to be revealed, on account of the potential damage to the commercial entity that has provided such information to the regulator for the purpose of obtaining registration of a medicine or medical device. In this regard, the recommendations of the US and European authorities on what should not be considered privileged information are instructive. Among the recommendations of the Blueprint for Transparency at the US Food and Drug Administration (FDA) are that the regulator routinely disclose basic information about the filing of applications for marketing authorisation, including for generic medicines, and the existence of clinical holds on clinical trials. ${ }^{[19]}$ In particular, it is recommended that the FDA ' $[\mathrm{m}]$ ake pooled data sets, masked and deidentified as appropriate, and the FDA's analyses of these data sets, available to the medical and research community through clinical data repositories.[19] Such analyses have traditionally been regarded as confidential, and not to be disclosed to any party other than the applicant for marketing authorisation. The European Medicines Agency (EMA) has noted the 'growing demand from stakeholders for additional transparency, not only about the Agency's deliberations and actions, but also about the clinical data on which regulatory decisions are based! ${ }^{[20]}$
The reference to 'self-gain' and 'benefit' indicates that the legislature had contemplated that such information would have value to other parties such as competitors. The purpose of this provision is therefore to protect parties who submit sensitive and potentially valuable information to the NMRA when seeking regulatory approval from suffering prejudice through unauthorised disclosure. However, the provision appears to have overlooked the significant public-health interests that might be advanced by ensuring timely access to such information.

In enacting section 34 of the Medicines Act, it appears that the legislature intended to take a firm stance regarding unauthorised use of information. The provision is therefore drafted in broad terms to prevent any circumvention or liberal interpretations that would allow those who would breach this provision to escape the appropriate sanction. Section 34 appears to provide the MCC/SAHPRA with broad discretion to refuse access to information, with the exception of the limited grounds mentioned therein. Significantly, the MCC/SAHPRA is not required to provide any justification for its refusal to accede to any request for information. The temptation is therefore to apply this provision in a blanket manner, and opt not to place any information that is in the slightest part useful to a competitor, such as the fact that an application for registration has been lodged, in the public domain. Another default position is to fail to provide the scientific basis for regulatory decisions, including analyses and findings with regard to clinical evidence of safety and efficacy. Communication is often limited to the minimum information mandated by section 22 of the Medicines $\mathrm{Act}^{\left[{ }^{[7]}\right.}$ and that required to be published in the register of medicines. There is a legitimate public interest in knowing whether an application for a particular medicine or medical device is being considered by the NMRA, as well as the detailed justification for either positive or negative decisions with regard to such an application.

\section{A comparison of section 34 with similar provisions in other jurisdictions The African Union Model Law on Medical Products Regulation}

It is useful to compare section 34 of the Medicines Act with another, similar provision, article 34 of the African Union Model Law on Medical Products Regulation ${ }^{[2]}$ (the Model Law), which states that:

'1) No person shall disclose to any other person or institution any information acquired by him in the exercise of his powers or the performance of his functions under this Law and relating to the business or affairs of any person, or use such information for self-gain or the benefit of his employer.

A person may be permitted to disclose information:

(a) for the purpose of the exercise of his powers or the performance of his functions under this law with the written authority of the agency/authority

(b) when required to do so by any competent court or under any law, or

(c) if it is in the public interest.'

This provision, like section 34 of the Medicines Act, prohibits the unauthorised disclosure of information, but contains a few key distinctions. The first difference is the seemingly minor addition of 'or institution' following the prohibition of unauthorised disclosure to any other person. The effect of this is to extend the reach of the 
provision so that it applies not only to disclosure to persons but any other institution that may not fall into the category of natural or juristic persons. The most significant difference between these two provisions is contained in section 2(c) of article 34. This subsection incorporates a qualification to the refusal of access to information, and refers directly to the public interest. The effect of this is that unlike in section 34 of the Medicines Act, article 34 of the Model Law requires all refusals to be balanced against the public interest, similar to the provisions of section $46(\mathrm{~d})$ of PAIA. ${ }^{[8]}$ The implication of this provision is that there can be no refusal if disclosure is in the public interest, and consequently, that the refuser will have to satisfy this requirement. No such justification is required under section 34 of the Medicines Act.

Following its adoption by the African Union, member states are obliged to take steps to domesticate the Model Law by, for example, bringing domestic legislation in line with the principles entrenched in the Model Law.

\section{European Medicines Agency transparency policy}

The EMA has adopted a proactive approach to enhancing transparency by issuing a policy on publication of clinical data for medical products for human use. ${ }^{[20]}$ The policy was designed primarily to promote access to information held by the medicines regulator through an online database that is publicly accessible. As stated in the policy: 'The Agency is committed to continuously extend its approach to transparency and has, therefore, taken the initiative to develop a policy on publication of clinical data.[20] The policy relates to clinical data, composed of clinical reports and individual patient data. Nonetheless, the policy provides for the appropriate protection of information it categorises as 'commercially confidential information', defined as 'any information contained in the clinical reports submitted to the Agency by the applicant that is not in the public domain or publicly available, and where disclosure may undermine the legitimate economic interest of the applicant'.[20] Accordingly, such information is not published, and is redacted from published documents where necessary. Despite this approach, the policy has been challenged in the European courts, ${ }^{[22]}$ and remains contested. ${ }^{[23]}$

\section{The UK Freedom of Information Act}

Section 1 of the UK Freedom of Information Act of $2000^{[23]}$ states that:

(1) Any person making a request for information to a public authority is entitled -

to be informed in writing by the public authority whether it holds information of the description specified in the request, and

if that is the case, to have that information communicated to him.

In contrast to section 34 of the Medicines Act, this provision places emphasis on access to information. It makes mandatory the disclosure of information subject to a request to a public body, and requires the public body to state whether it has the relevant information. These requirements facilitate transparency in relation to information held by public bodies.

\section{The US Federal Food, Drug, and Cosmetic Act}

Section 301(j) of the Federal Food, Drug, and Cosmetic Act (FFDCA) of $1938,{ }^{[24]}$ the statute that regulates the US NMRA, the Food and Drug Agency (FDA), prohibits:
'The using by any person to his own advantage, or revealing, other than to the Secretary or officers or employees of the Department, or to the courts when relevant in any judicial proceeding under this Act, any information acquired under authority of section $404,409,412,414,505,510,512,513,514,515,516,518,519$, $520,571,572,573,704,708,721,904,905,906,907,908,909$, or 920 (b) concerning any method or process which as a trade secret is entitled to protection; or the violating of section 408(i)(2) or any regulation issued under that section.

This provision, similarly to section 34 of the Medicines Act, prohibits persons using information that they acquire as a consequence of their authority in the agency for their own advantage or any other unauthorised disclosure. Despite this, it does not act as a blanket prohibition on the disclosure of all information to third parties, but specifically refers to information that is entitled to protection under the Act as a trade secret. This would appear to allow for the disclosure of information where it would be in the public interest, provided it did not include such specifically protected information. Accordingly, although often heavily redacted, the FFDCA places considerable resources in the public domain, including detailed accounts of deliberations of the advisory committees that inform decisions of the FDA. Together with a wide range of stakeholder groups, the FDA adopted the Blueprint for Transparency at the FDA, and provides for greater transparency of information held by the regulator, as alluded to above. ${ }^{[19]}$ In response to concerns about research-participant confidentiality, the blueprint calls for the following approach: 'When clinical-trial data, including patient-level data, are not available to independent investigators through industry-sponsored websites, make data available through clinical-data repositories, with policies on deidentification to protect patient privacy.'

\section{Analysis of authorities}

Section 32 of the Constitution entrenches access to information as a fundamental right. ${ }^{[1]}$ PAIA places great emphasis on access to information as a cornerstone of the transparency of state entities and public bodies. ${ }^{[8]}$ The right to access to information, among others, seeks to make a clean break from the abuse of state power characterised by the apartheid system. This explains PAIA's insistence on providing access to any information held by the state, as opposed to access to information held by private bodies. Given the gravity attached to the right of access to information in the context of public bodies, where such access is refused it must be for a specified and clear reason that is not outweighed by the 'public interest', as required by section $46{ }^{[8]}$ Moreover, the refuser bears the onus of demonstrating that the refusal is justified under the law.

Section 34 of the Medicines Act therefore appears to be in conflict with the values and rights entrenched in the Constitution and, more particularly, PAIA. This section, in effect, appears to grant the MCC/ SAHPRA unfettered authority to refuse access to information, except on limited grounds, based on its sole discretion. The limitation clause in the Constitution provides that any limitation of a right must be reasonable and justifiable. Applying the reasonable-limit test to section 34 , it is clear that, while limiting access to information where it would advance personal interests is relevant, and the decision to refuse access to information is rationally connected to the objective of prohibiting unauthorised access to information, the broadness of section 34 impairs 
the right of access to information to a greater extent than is absolutely necessary and justifiable. Section 34 has its genesis in the predemocracy legislation, and clearly does not take into account the constitutional paradigm. Its effect is to deprive the public of access to key information that may be of benefit to society, and gives the MCC/SAHPRA unfettered discretion to deny such access without the requisite openness and transparency required by the Constitution. The restrictions placed on access to information are therefore disproportional to the interest of preventing harm to third parties.

The principle of constitutional validity of legislation was visited by the Constitutional Court in SANDU [SA National Defence Union] v Minister of Defence. ${ }^{[24]}$ The court had to decide whether a provision prohibiting members of the national defence force from being members of trade unions was constitutional. In reaching its conclusion, the court set out the following test for examining whether or not a particular law is unconstitutional:

'The first question to be asked is whether the provision in question infringes the rights protected by the substantive clauses of the Bill of Rights. If it does, the next question that arises will be whether that infringement is justifiable. At the second stage of the Constitutional inquiry, the relevant questions are what is the purpose of the impugned provision, what is its effect on Constitutional rights and is the provision well-tailored to that purpose. ${ }^{[24]}$

The court held that the relevant provisions contained 'a sweeping prohibition, whose consequence is a grave incursion on the fundamental rights of soldiers. The provisions cannot be justified by reference to the need to ensure that uniformed military personnel do not engage in politically partisan conduct.'[24] It held that the prohibition, despite being connected to a rational end (the need to ensure that uniformed military personnel do not engage in politically partisan conduct) was not sufficient to justify the infringement of their rights. The court accordingly found that the provisions were inconsistent with the Constitution.

\section{Conclusion}

Despite multiple opportunities having arisen to revise the law, section 34 of the Medicines Act, a provision that encroaches on a fundamental right entrenched in the Bill of Rights, without the requirement to provide any justification, remains in effect. In light of the emphasis on transparency and accountability in both the Constitution and PAIA, it is suggested that such a blanket provision barring access to information would not pass muster as a 'limitation that is reasonable and justifiable in an open and democratic society based on human dignity, equality and freedom. ${ }^{[1]}$ It is accordingly submitted that section 34 of the Medicines Act is unconstitutional, to the extent that it violates the right to access to information in section 32 of the Constitution of SA, and should be amended in an appropriate manner to accommodate the fundamental right to access to information.

It is therefore recommended that the following measures be implemented:

(i) Section 34 should be amended to reflect the language and spirit of article 34 of the AU Model Law.

(ii) This should be supplemented by the appropriate guidelines on commercially confidential information, as elaborated above, and the inclusion of a positive obligation on the MCC/SAHPRA to maximise transparency, while allowing applicants the right to motivate what should be considered as commercially confidential information.

(iii) Finally, these legislative changes should ensure alignment with the provisions of PAIA and, in particular, the conditions and processes related to applications for access to information.

This is particularly important now that the $2008^{[5]}$ and 2015 Medicines Amendment Acts $^{\left[{ }^{[6]}\right.}$ have been promulgated ${ }^{[25]}$ and a new model of medicines regulation is being implemented. It provides an opportunity to redress a serious anomaly in our regulatory framework, and to align it with our constitutional paradigm, in order to reflect greater openness, transparency and accountability in our public institutions.

Acknowledgements. None.

Author contributions. Equal contributions.

Funding. None.

Conflicts of interest. The authors are serving members of the Medicines Control Council of South Africa, and write in their personal capacities.

1. South Africa. The Constitution of the Republic of South Africa, Act No. 108 of 1996

2. Wirtz VJ, Hogerzeil HV, Gray AL, et al. Essential medicines for universal health coverage. Lancet 2017;389(10067):403-476. https://doi.org/10.1016/s01406736(16)31599-9

3. Medicines and Related Substances Control Amendment Act 90 of 1997.

4. Medicines and Related Substances Amendment Act 59 of 2002.

5. Medicines and Related Substances Amendment Act 72 of 2008.

6. Medicines and Related Substances Amendment Act 14 of 2015

7. Medicines and Related Substances Act 101 of 1965, as amended.

8. South Africa. Promotion of Access to Information Act No. 2 of 2000.

9. S v Zuma and others 1995 (2) SA 642 (CC); 1995 (4) BCLR 401 (CC).

10. Regina v Big M Drug Mart Ltd; 1985 (1) SCR 295.

11. S v Makwanyane and Another (CCT3/94); 1995 ZACC 3.

12. R v Chaulk; 1990 (3) SCR.

13. R v Oakes; 19861 () SCR 103

14. Brummer v The Minister of Social Development and Others (CCT 25/09); 2009 ZACC 21.

15. South Africa. Public Finance Management Act No. 1 of 1999.

16. World Trade Organization. Agreement on Trade-Related Aspects Intellectual Property Rights. Geneva: WTO, 1995.

17. SA Airlink (PTY) Ltd v Mpumalanga Tourism and Parks Agency (01011/12) ZAGPHC 143.

18. Trustees For The Time Being of the Biowatch Trust v Registrar Genetic Resources and Others (23005/2002); 2005 ZAGPHC 135.

19. Sharfstein JM, Stebbins M. Enhancing transparency at the US Food and Drug Administration: Moving beyond the 21st Century Cures Act. JAMA 2017;317(16):1621-1622. https://doi.org/10.1001/jama.2017.2481

20. European Medicines Agency. EMA policy on publication of clinical data for medicinal products for human use (EMA/240810/2013). 2014. http://www.ema. europa.eu/docs/en_GB/document_library/Other/2014/10/WC500174796.pdf (accessed 8 July 2017).

21. African Union. AU Model Law on Medical Products Regulation, 2016. http://www. nepad.org/resource/african-union-au-model-law-medical-products-regulation (accessed 1 July 2017).

22. PTC Therapeutics International v EMA (T-718/15 R).

23. Kim D. Transparency policies of the European Medicines Agency: Has the paradigm shifted? Med Law Rev 2017;25(3):456-483.

24. United Kingdom. UK Freedom of Information Act $2000 \mathrm{http}: / / \mathrm{www}$. legislation.gov.uk/ukpga/2000/36/pdfs/ukpga_20000036_en.pdf (accessed 8 July 2017).

25. United States of America. US Federal Food, Drug and Cosmetic Act 1938 https://legcounsel.house.gov/Comps/Federal\%20Food,\%20Drug,\%20And\%20 Cosmetic\%20Act.pdf (accessed 8 July 2017).

26. SANDU v Minister of Defence (CCT27/98) 1999 ZACC 7

27. South Africa. Proclamation Notice 20 of 2017, Government Gazette No. 40869. 2017.

Accepted 2 November 2017 